
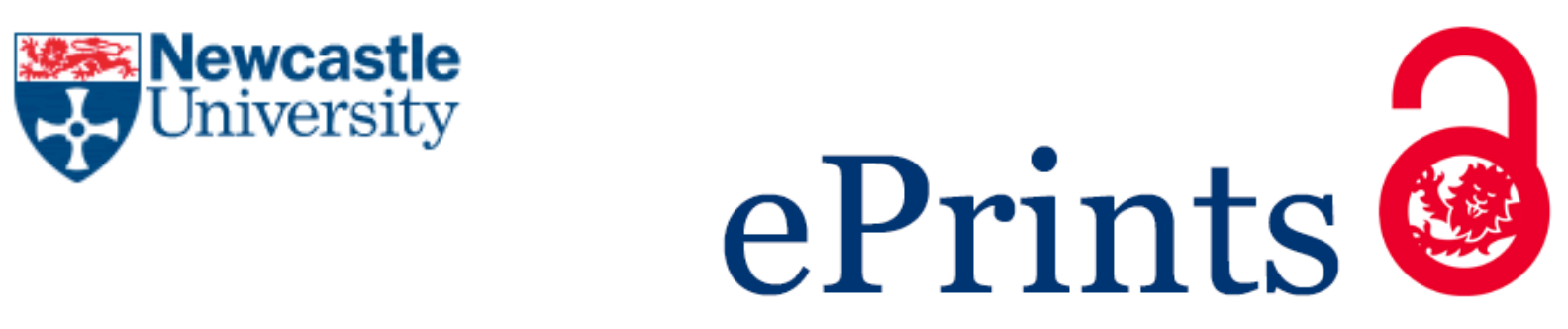

Gupta G, Wu B, Mylius S, Offer GJ.

A systematic study on the use of short circuiting for the improvement of proton exchange membrane fuel cell performance. International Journal of Hydrogen Energy 2017, 42(7), 4320-4327.

\title{
Copyright:
}

(C) 2017. This manuscript version is made available under the CC-BY-NC-ND 4.0 license

DOI link to article:

http://dx.doi.org/10.1016/j.ijhydene.2016.10.080

Date deposited:

$02 / 08 / 2017$

Embargo release date:

10 November 2017

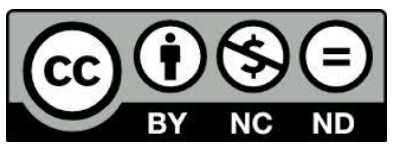

This work is licensed under a

Creative Commons Attribution-NonCommercial-NoDerivatives 4.0 International licence 


\section{A systematic study on the use of short circuiting for the improvement of proton} exchange membrane fuel cell performance Gaurav Gupta ${ }^{1, *}$, Billy Wu ${ }^{2}$, Simon Mylius ${ }^{3}$ and Gregory J. Offer ${ }^{1}$ ${ }^{1}$ Department of Mechanical Engineering, Imperial College London, UK

${ }^{2}$ Dyson School of Engineering, Imperial College London, UK

${ }^{3}$ Arcola Energy, London, UK

\section{Abstract}

Proton exchange membrane fuel cells suffer from reversible performance loss during operation caused by the oxidation of the Pt catalyst which in turn reduces the electrochemically active surface area. Many fuel cell manufacturers recommend using short circuiting during the operation of the fuel cell to improve the performance of the cells over time. However, there is lack of understanding on how it improves the performance as well as on how to optimise the short circuiting strategy for different fuel cell systems. We present a simple procedure to develop an optimised short circuiting strategy by maximising the cumulative average power density gain and minimising the time required to recover the energy loss during short circuiting. We obtained average voltage improvement from 10 to $12 \%$ at different current densities for commercial H-100 system and our short circuiting strategy showed $2 \%$ voltage improvement in comparison to a commercial strategy. We also demonstrated that the minimum short circuiting time is a function of double layer capacitance by the use of electrochemical impedance spectroscopy.

Keywords: Proton exchange membrane fuel cells, short circuit, Pt oxidation, degradation

\footnotetext{
${ }^{*}$ Corresponding author

Dr. Gaurav Gupta Department of Mechanical Engineering, Imperial College London, South Kensington UK- SW7 2AZ

Email: g.gupta@imperial.ac.uk
} 


\section{Introduction}

Proton exchange membrane fuel cells have been present for many decades however large scale commercialisation has still yet to be achieved. The major factors that are hindering this are the low cathodic catalytic activity, lower lifetime of the fuel cells and use of expensive Pt as catalyst which makes it more expensive to compete in the current market [1-3]. A lot of research has been focussed on discovering new catalyst materials ranging from Pt based alloys to non Pt based alloys to improve the catalytic activity, lower the use of Pt to reduce the cost of the system while at the same time trying to improve the lifetime of the fuel cell [4-13]. However, one of the major factors which is often overlooked is the performance loss of the fuel cell during operation. This can increase the cost of the system as the system has to be oversized to accommodate the performance loss. One cause of this performance loss is due to the formation of oxide layers on the platinum $(\mathrm{Pt})$ catalyst which reduces the current density at a given potential. The oxidation of Pt occurs as a natural intermediate in the oxygen reduction reaction (ORR) and hence cannot be avoided entirely, as it is why platinum is such a good fuel cell catalyst. The reactions can be summarised below, although it should be noted there is a wealth of detail and some controversy in the academic literature $[2,3,13-16]$ as to the exact reaction pathway in practice:
Adsorption

$$
2 \mathrm{Pt}+\mathrm{O}_{2} \rightleftharpoons \mathrm{Pt}_{2} \mathrm{O}_{2}
$$

Dissociation

$$
\mathrm{Pt}_{2} \mathrm{O}_{2} \rightleftharpoons 2 \mathrm{PtO}
$$

Reduction 1

$$
\mathrm{PtO}+\mathrm{H}^{+}+e^{-} \rightleftharpoons \mathrm{PtOH} \quad \mathrm{E}^{\mathrm{o}}=1.1-1.4 \mathrm{~V} \text { vs SHE }
$$

Reduction 2

$$
\mathrm{PtOH}+\mathrm{H}^{+}+e^{-} \rightleftharpoons \mathrm{PtH}_{2} \mathrm{O} \quad \mathrm{E}^{\mathrm{o}}=0.85-1.1 \mathrm{~V} \text { vs SHE }
$$

Desorption

$$
\mathrm{PtH}_{2} \mathrm{O} \rightleftharpoons \mathrm{Pt}+\mathrm{H}_{2} \mathrm{O}
$$

Each of the electrochemical reactions, (3) and (4) have an equilibrium potential, and so there will be an equilibrium coverage of species on the surface that is a function of the operating cathode potential. Hence at different potentials there are different equilibrium concentrations 
1 of species, meaning that there are more or less free sites available for oxygen to adsorb on the

2 platinum (i.e. reaction (1)). Thus, the reaction intermediates can also be considered poisons to

3 the reaction, as if their concentration builds up too high they can limit the current density at a

4 given potential. Fortunately, because all the species adsorbed on the surface are in dynamic

5 equilibrium with each other, the equilibrium concentration for a given potential takes time to

6 be established, and therefore, it is possible to achieve a time averaged concentration of

7 intermediate species that is different from the equilibrium concentration for a given potential,

8 by periodic perturbation of the system (i.e. short circuiting).

There are various reports which highlight the formation of $\mathrm{H}_{2} \mathrm{O}_{2}$ as an intermediate

10 during the oxygen reduction reaction $[2,3,13,17,18]$. This $\mathrm{H}_{2} \mathrm{O}_{2}$ formation not only reduces

11 the efficiency of the fuel cell system but also accelerates degradation of the Nafion membrane by the formation of free radicals [14, 17-22]. It may be possible to avoid the formation of the peroxides if the average coverage of $\mathrm{OH}$ can be reduced by short circuiting, thereby reducing the degradation due to low voltage idling conditions.

There are a very limited number of publications on the use of short circuiting as a method to improve the performance of fuel cell systems. In early 2000, a patent by Fuglevand et. al [23] was published on the use of short circuiting with fuel cells for the performance improvement of the system and they attributed this performance increase to the increase in proton conductivity of the membrane because of two reasons : 1) more water production and

2) increase in temperature to evaporate water and increase air flow to the cathode. Koschany et.al [24] also recommended the use of short circuiting to improve the performance of the fuel cell by maintaining the water content. In contrast Pearson et.al $[25,26]$ secured a patent on the method and apparatus for improving the performance of fuel cells by periodically short circuiting. They believed the performance improvement was due to the stripping of oxides and other adsorbed species from Pt. This patent led to the commercialisation of a short circuiting 
1 controller by Ballard systems with their fuel cell stacks. Other fuel cell system suppliers, such

2 as Horizon fuel cells, also use a short circuiting controller which does a short circuit for 100

3 ms every $10 \mathrm{~s}$ of operation but does not vary with the condition of the stack. Some studies on

4 the use of short circuiting has been reported by researchers in academia as well where Kim

5 et.al [27] used this technique to humidify the stack for unmanned aerial vehicle and Zhan et.al

6 [28] reported improvement in performance and lifetime for use of fuel cell in hybrid

7 applications. Both studies reported the production of excess water during the short circuiting

8 as the reason for performance improvement and also the moisture evaporation from the GDL.

9 Despite the fact that it works, there is still a lack of clear evidence for the mechanism for 10 improving the performance and there are two competing theories. There is also no published 11 strategy on how frequently and how long the short circuiting should be done.

Examining the two theories for why short circuiting improves performance, it is easy to quickly discard the water/thermal management theory. Consider that a typical short circuit period might be $100 \mathrm{~ms}$ every $10 \mathrm{~s}$, and that during the short circuit the current and therefore amount of water produced during this time might double. However, the time during short circuit represents only $1 \%$ of the total operating time. Thus only $1 \%$ more water in total will be produced by the short circuit. We consider this to be highly unlikely to have a significant effect on the water management of the fuel cell system, except perhaps the local concentration of water in the catalyst layer. Secondly the argument that short-circuiting will increase the temperature and hence evaporate water and increase air flow to the cathode, can also be discarded. Consider that during the short circuit, the system runs at $0 \mathrm{~V}$, and so it is true that all energy generated will be dissipated as heat internally. This could indeed lead to a sudden increase in temperature at localised points which could evaporate water at those points.

24 However, again the short circuit represents only $1 \%$ of the total operating time. In addition, the purpose of the short circuit is that the average voltage increases, and hence the efficiency of 
1 the fuel cell increases and the heat generated during the remaining $99 \%$ of the time is less. This

2 means less total heat overall will be produced, and thus the stack should be cooler, which could

3 increase the risk of flooding. Therefore by Occam's razor $[29,30]$ we assume that the oxide

4 stripping mechanism, as the simplest theory, is correct.

It is very important to understand the relationship between the kinetics and

6 thermodynamics of oxide formation in order to predict the mechanism of oxide removal. Pt

7 oxidation is severe at the higher potentials and thus should need more frequent short circuiting

8 and less at lower potentials. The short circuiting time will depend on the discharging of the

9 double layer capacitance and thus the minimum short circuiting time should exceed the time

10 needed to discharge the double layer, but not too long to cause fuel or air starvation, and thus

11 there should be an optimum time depending on the performance enhancement as well as

12 application. There has been a recent study by Rinaldo et. al [31] wherein the relationship

13 between kinetics and thermodynamics of oxide formation and reduction was studied using

14 cyclic voltammetry. They used a potentiodynamic model to study the different stages of oxide

15 formation and reduction by including reaction rates that are dependent on the species and

16 adsorption energies. They were able to model the behaviour of Pt (111) and predict the

17 irreversibility of the $\mathrm{CV}$ and relate it to the two-site non-electrochemical surface reaction taking

18 place at high potential. However, the model was only validated for the Pt (111) surface and

19 failed to predict the behaviour in case of polycrystalline Pt which is normally the catalyst used

20 in fuel cell.

21 In summary the short circuiting method has been well known to industry for many years and even commercialised by Ballard and Horizon, however there is a lack of understanding on

23 how it actually improves the performance. There have also been no studies on how to optimise 24 a short circuiting strategy for different fuel cell systems. This paper presents an experimental 
1 study of the technique, and also the development of a methodology to establish the optimum

2 short-circuiting strategy for any system.

3

\section{Experimental Methods}

The short circuiting strategy was developed by testing on a 2 cell setup made from selfhumidifying cells provided by Arcola Energy. It is a closed cathode system with an active area of $144 \mathrm{~cm}^{2}, 3$ channel serpentine and parallel flow channels were used for the anode and cathode respectively. Stoichiometry of 1.3 and 3 were used for $\mathrm{H}_{2}$ and Air, respectively. None of the gases were humidified and the relative humidity of $\mathrm{H}_{2}$ and air were $\sim 0 \%$ and $10-15 \%$, respectively. A simple block diagram for the test setup is given in Figure 1(a). The load bank used was Scribner 850 e and Labview was used to control the short circuiting. The switching between normal operation and short circuiting was done with the help of two switches shown in block diagram as load switch (LS) and short circuit (SC). For normal operation of the fuel cell, LS is closed while SC is open and to induce a short circuit first the LS switch is opened and SC is closed. Cell voltage and current during short circuit was monitored using a National Instruments (NI) compactRIO (cRIO) at $1 \mathrm{kHz}$ with a $12 \mathrm{bit} \pm 10 \mathrm{~V}$ analog input module. The testing was done at $69.4 \mathrm{~mA} / \mathrm{cm}^{2}\left(25^{\circ} \mathrm{C}\right), 138.9 \mathrm{~mA} / \mathrm{cm}^{2}\left(30{ }^{\circ} \mathrm{C}\right)$ and $277.8 \mathrm{~mA} / \mathrm{cm}^{2}\left(50{ }^{\circ} \mathrm{C}\right)$ for different short circuiting times of $10 \mathrm{~ms}, 50 \mathrm{~ms}, 100 \mathrm{~ms}, 200 \mathrm{~ms}$ and $500 \mathrm{~ms}$ to find the short circuiting interval which will give the maximum increase in the performance i.e. higher cell voltage. A schematic of the short circuiting protocol is shown for 4 short circuits in Figure 1(b). However, the amount of short circuits were varied during the testing. During the experiments, a load is applied to the fuel cell until it reached a steady state voltage. A short circuit is applied to find the maximum power increase which was then set as the short circuiting interval, this process was then repeated by doing 10 short circuits using the set short circuit duration and interval to verify the improved performance. 


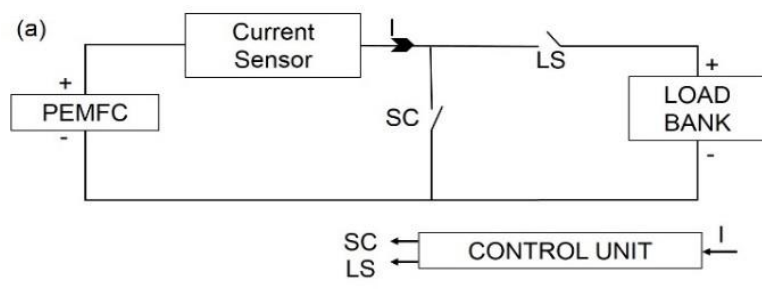

1 conditions.

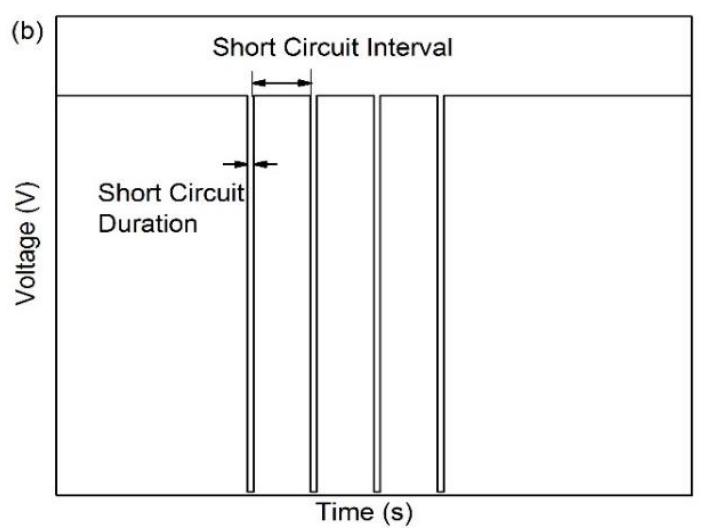

Figure 1: Schematic of the (a) short circuiting setup and (b) short circuiting protocol

After the formation of a short circuiting strategy using the 2 cell setup, this strategy was verified by application in a commercial Horizon $\mathrm{H}-100$ fuel cell stack which is an open cathode system consisting of 20 cells in the stack each with an active area of $22.5 \mathrm{~cm}^{2}$. Two systems were used, a new H-100 system and a system that has been tested aggressively since 2014 and has degraded over time such that its maximum performance was around $40 \%$. This was to test the hypothesis that a single optimisation strategy could be applied to stacks in different

The testing was done at 3 different current values in the range of $0.6 \mathrm{~V}$ to $0.75 \mathrm{~V}$ which can be termed as the region where performance is thought to be dominated by the effect of $\mathrm{PtOH}$ and PtO. The testing was done at $44.4 \mathrm{~mA} / \mathrm{cm}^{2}\left(22^{\circ} \mathrm{C}\right), 88.9 \mathrm{~mA} / \mathrm{cm}^{2}\left(25^{\circ} \mathrm{C}\right)$ and 133.3 $\mathrm{mA} / \mathrm{cm}^{2}\left(30^{\circ} \mathrm{C}\right)$ and the in-built controller was removed and replaced by the short circuiting controller used for the 2 cell system. The systems were conditioned by the procedure recommended by Horizon Fuel Cell systems to bring them to maximum efficiency. The testing was done at the same current values for both systems but the new $\mathrm{H}-100$ system was also tested at $266.7 \mathrm{~mA} / \mathrm{cm}^{2}\left(38{ }^{\circ} \mathrm{C}\right)$ chosen so as to not exceed the $100 \mathrm{~W}$ power limit. The testing was done with hydrogen flowing through the system with no purging to exclude the effect of purging on the performance improvement. A fuel stoichiometry of 1.3 was used for $\mathrm{H}_{2}$ and atmospheric air was used with operating the in-built fan at $5 \mathrm{~V}$ to maintain the temperature and 
1 sufficient air supply for reaction. Dry hydrogen was used with a relative humidity of $\sim 0 \%$ and

2 the relative humidity of atmospheric air varied between $40-45 \%$ over the course of testing.

3 Electrochemical impedance spectroscopy was done at different current values to find the time

4 constant of the electrical double layer. The measurements were performed using an Autolab

5 potentiostat for $\mathrm{H}-100$ stacks under load within a frequency range between $10 \mathrm{kHz}$ and $0.1 \mathrm{~Hz}$

6 with an amplitude of $5 \%$ of the DC current. The spectra was recorded after the potential had

7 stabilised for the specified current value i.e. $1 \mathrm{~A}\left(44.4 \mathrm{~mA} / \mathrm{cm}^{2}\right), 2 \mathrm{~A}\left(88.9 \mathrm{~mA} / \mathrm{cm}^{2}\right), 3 \mathrm{~A}(133.3$

$\left.8 \mathrm{~mA} / \mathrm{cm}^{2}\right), 6 \mathrm{~A}\left(266.7 \mathrm{~mA} / \mathrm{cm}^{2}\right)$ in the current study.

\section{$9 \quad$ Results and Discussion}

Figure 2 shows the voltage profile recorded at $69.4 \mathrm{~mA} / \mathrm{cm}^{2}$ for the 2-cell setup which was subjected to a single short circuit from $10 \mathrm{~ms}$ to $500 \mathrm{~ms}$. Results for other two current values $\left(138.9 \mathrm{~mA} / \mathrm{cm}^{2}\right.$ and $\left.277.8 \mathrm{~mA} / \mathrm{cm}^{2}\right)$ are reported in supporting information (Figure $\mathrm{S} 1$ and S2). First the 2-cell setup was held at $69.4 \mathrm{~mA} / \mathrm{cm}^{2}$ for $10 \mathrm{mins}$ to reach a steady state as can be seen by the plateau on the potential curve, then a short circuit (which appears as spikes on the graph) was applied for different time periods i.e. $10 \mathrm{~ms}, 50 \mathrm{~ms}, 100 \mathrm{~ms}, 200 \mathrm{~ms}$ and 500 ms. It can be clearly seen from the curve that the short circuiting time of $10 \mathrm{~ms}$ was not enough to induce any gain in the potential. All other short circuiting times showed a similar profile of increase in the potential and then a gradual decline. This confirms that the short circuit duration must exceed the time taken to discharge the double layer, and that for times greater than this a potential increase can be induced which can result in the increase of power. However, the maximum amount of short circuiting time should be kept to a minimum so as not to induce any permanent damage to the fuel cell and to achieve maximum power gain. This improvement in the potential is due to the removal of the Pt hydroxide and oxide layers formed on the Pt catalyst and thus resulting in a larger effective surface area of Pt available for the electrochemical reaction. If short circuiting is not performed Pt hydroxide and oxide will continuously form, 
1 and with time the potential will decay gradually as can be seen in Figure 2. In order to find the 2 amount of performance improvement from the short circuiting, cumulative average power 3 density gain per cell was calculated taking into account the power decrease during the short 4 circuit.
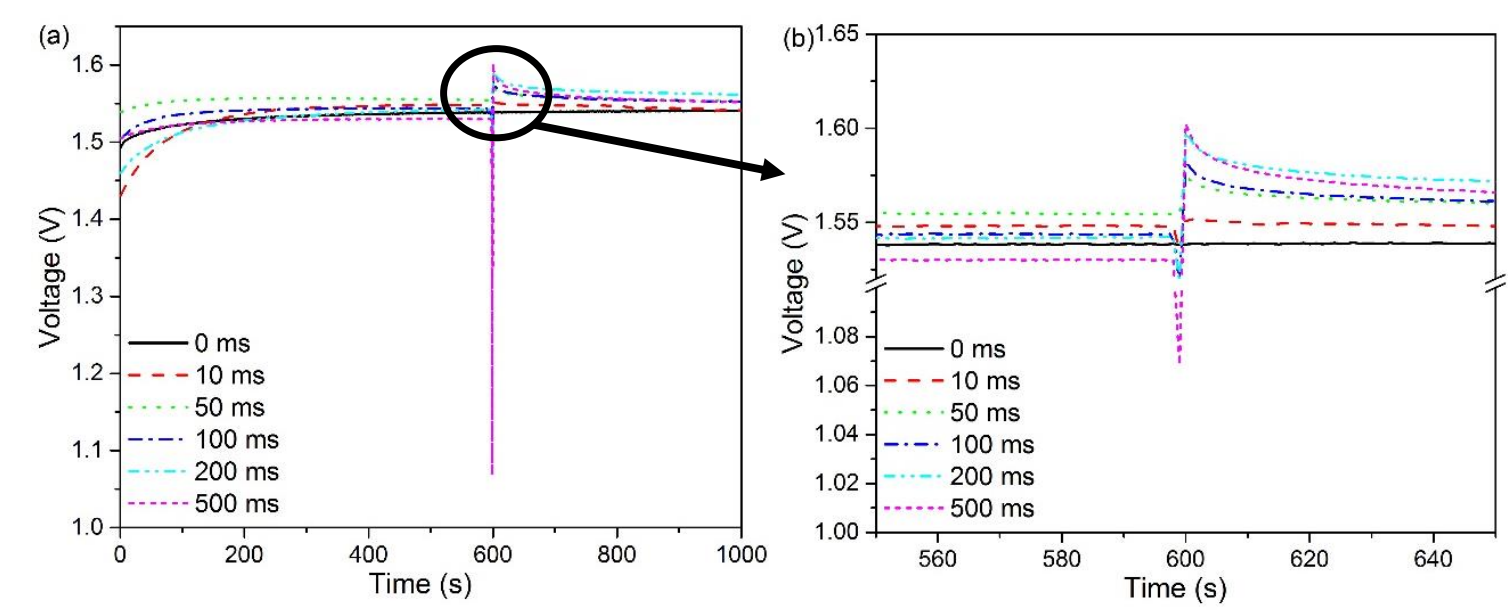

Figure 2: Potential vs time comparison for short circuiting at $69.4 \mathrm{~mA} / \mathrm{cm}^{2}\left(25^{\circ} \mathrm{C}\right)$ for Arcola 7 8 2 cell setup at different short circuit time period
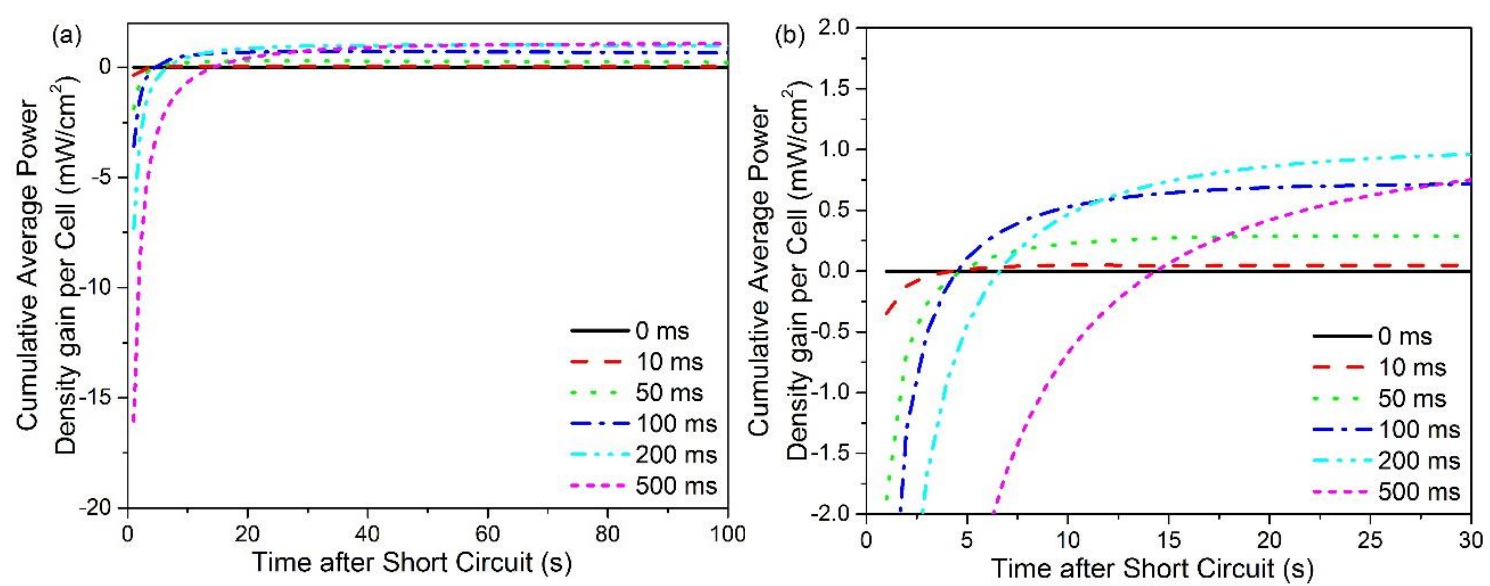

Figure 3: Cumulative average power density gain per cell at different short circuiting time for short circuiting at $69.4 \mathrm{~mA} / \mathrm{cm}^{2}\left(25^{\circ} \mathrm{C}\right)$ on Arcola 2 cell setup.

Figure 3 shows a relationship between the cumulative average power density gain per

14 cell with the increase of short circuiting time as a function of time after the short circuit. Sample

15 calculation for cumulative average power density gain per cell is shown in supporting information S4. It can be clearly seen that the short circuiting time of $10 \mathrm{~ms}$ is a flat line very near to 0 and thus offers no significant improvement in performance. With the increase in short 
1 circuiting time, the point at which the cumulative power density gain becomes a net positive

2 start shifting towards the right i.e. it takes longer to recover the energy loss incurred during

3 short circuiting. This is likely due a number of reasons. Firstly the double layer will become

4 increasingly discharged at longer short circuit durations and thus requiring additional time to

5 be recharged. Secondly, at these potentials the oxides are likely to be removed quickly and they

6 have a finite coverage. Therefore there is a fixed amount of time (or charge) needed to remove

7 them, and once this is exceeded any further time spent during short-circuit is unnecessary and

8 wastes energy. Figure 3 also shows the cumulative average power density increasing with

9 increase in short circuiting time. This reaches a maximum and then starts decreasing. This time

10 could therefore be around the optimum time needed to remove the oxides. So, in order to

11 develop an optimum strategy, the cumulative average power density gain should be maximised

12 by minimising the time taken to recover the energy loss during the short circuit. Based on these

13 two criteria, a short circuiting time between 100 and $200 \mathrm{~ms}$ is the optimum short circuiting

14 time for this system. To test this strategy, multiple short circuits were done at $69.4 \mathrm{~mA} / \mathrm{cm}^{2}$

15 with a short circuiting time of $100 \mathrm{~ms}$ and interval of $36 \mathrm{~s}$ (point of maximum cumulative 16 average power density gain).

Figure 4 shows the comparison between the 2 cell setup run without short circuiting and with the short circuiting strategy. A 3\% increase in the performance was observed for the system run using short circuits. The low performance improvement is due to the only 2 cells in

20 the system and also running of the system at a very low current density. Thus even though the 21 potential increase is by $50 \mathrm{mV}$, the change in performance is only by $3 \%$. From Figure 4 (b), it can be seen that with every cycle, there is an improvement in the performance and after around 7-8 cycles it has reached a dynamic equilibrium. The results show that one short circuit is not enough to achieve the maximum performance gain but requires multiple short circuits. As discussed in figure 2 that the voltage improvement is due to the removal of Pt hydroxides 
1 and oxides from the Pt catalyst. However, one cycle of short circuiting is not enough to recover

2 the maximum performance and thus multiple short circuits are needed. This becomes clear

3 from Figure 4 that with multiple short circuits, the voltage gain is increasing and becomes

4 constant after $\sim 7$ cycles.

5
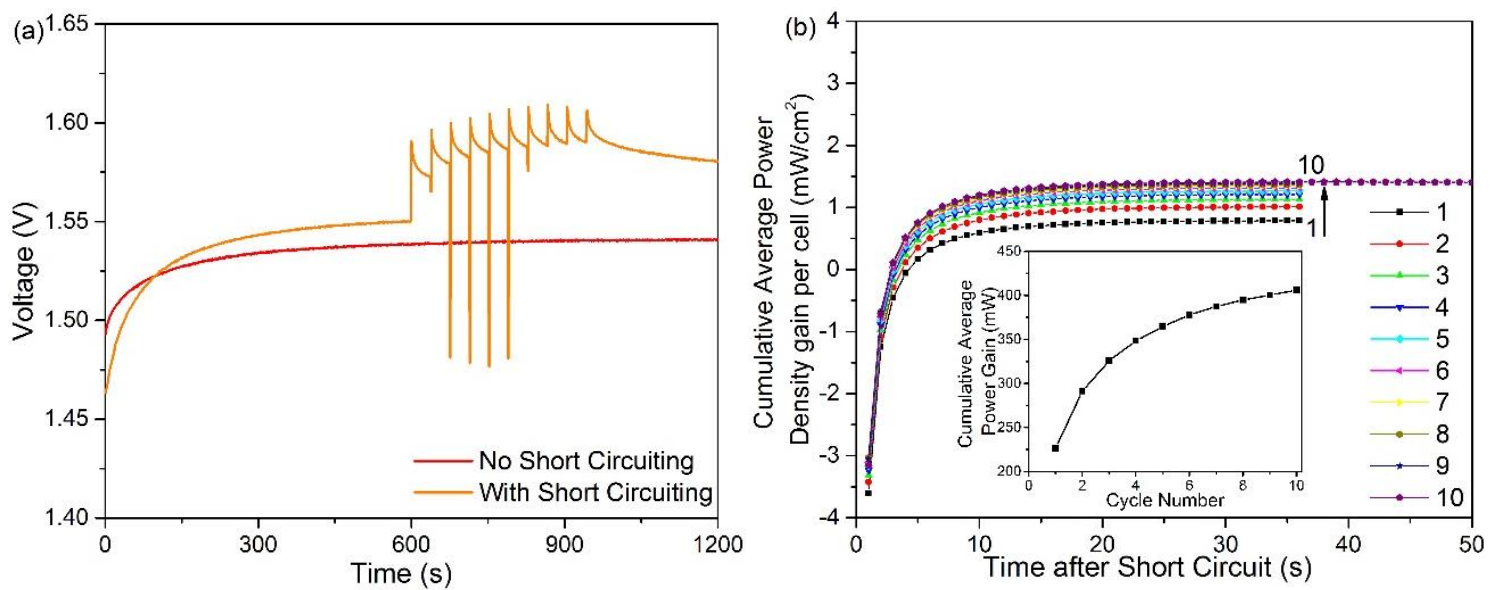

Figure 4: (a) Potential profile at $69.4 \mathrm{~mA} / \mathrm{cm}^{2}$ without and with $10 \mathrm{SC}$ cycles (SC time-100 $\mathrm{ms}$ and interval of $36 \mathrm{~s}$ ). (b) Cumulative average power density gain profile for each short circuiting cycle.

The parametric short circuiting strategy developed above was then verified on a commercial Horizon H-100 system. A single short circuit was done at different current densities for different short circuiting times and short circuiting intervals, the optimum were found by the analysis of cumulative average power density gain per cell (Figure S3 for 44.4 $\mathrm{mA} / \mathrm{cm}^{2}$ ). This was the same procedure as that developed using the 2 cell Arcola Energy system. From the analysis of these results, the optimum short circuiting time was again between 100 and $200 \mathrm{~ms}$. As Horizon recommends using a short circuiting strategy of short circuiting time - $100 \mathrm{~ms}$ and interval $-10 \mathrm{~s}$, for a good comparison the short circuiting time of $100 \mathrm{~ms}$ was used with the short circuiting interval obtained from our strategy of obtaining maximum cumulative average power density gain. 

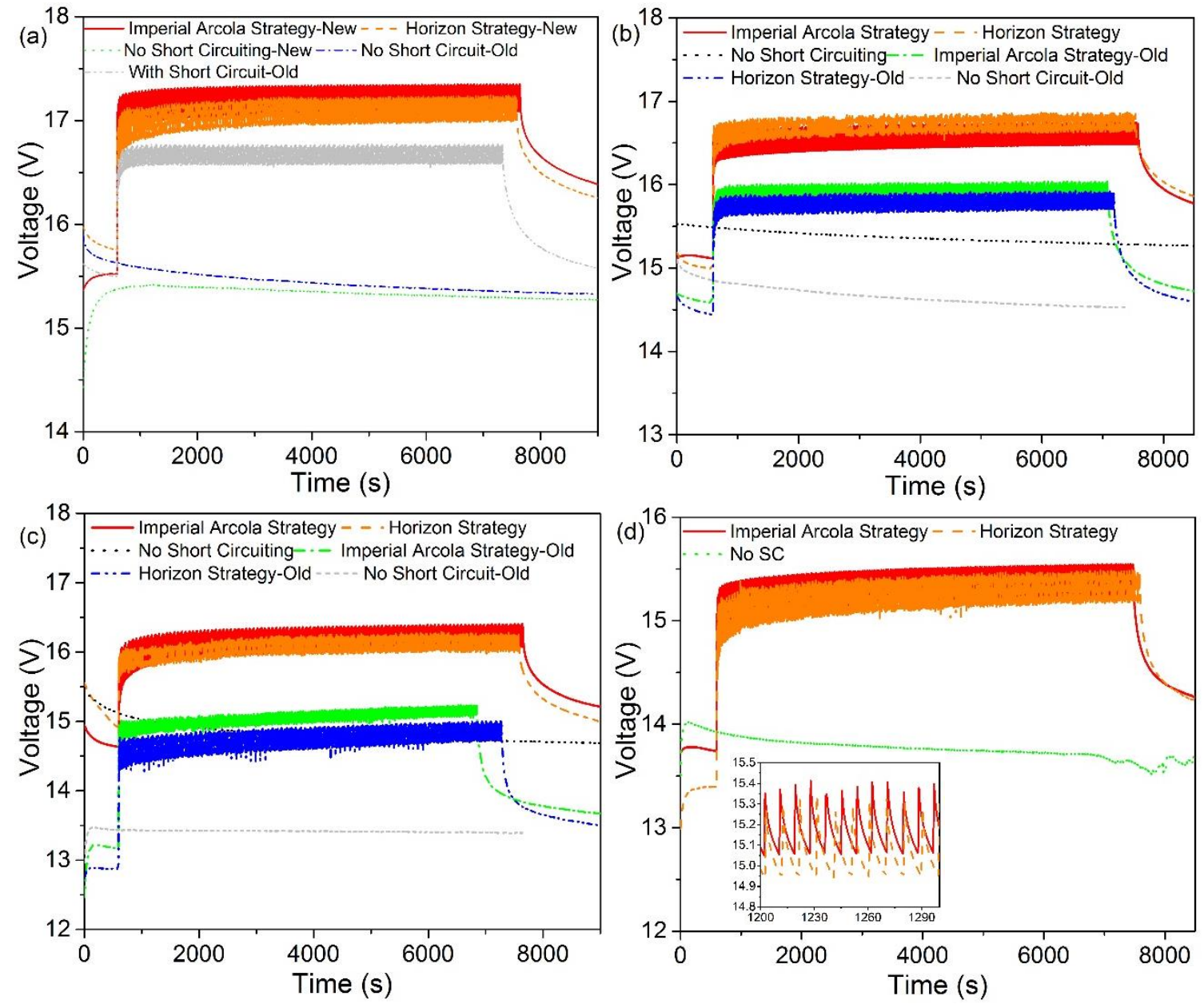

Figure 5: Potential comparison for short circuit testing using Imperial Arcola Strategy, Horizon Strategy and no short circuit at (a) $44.4 \mathrm{~mA} / \mathrm{cm}^{2}$, (b) $88.9 \mathrm{~mA} / \mathrm{cm}^{2}$, (c) $133.3 \mathrm{~mA} / \mathrm{cm}^{2}$ and (d) $266.7 \mathrm{~mA} / \mathrm{cm}^{2}$.

Figure 5 shows a comparison of the Horizon strategy, the developed strategy (Imperial Arcola strategy) and no short circuiting on the old and new H-100 systems at different current densities at a short circuiting time of $100 \mathrm{~ms}$. As mentioned earlier, the old H-100 system was tested aggressively for 2-3 years and can only deliver $40-45 \%$ of its rated power, and thus higher current density testing was not possible. The results from this system are labelled as old. Figure 5 (a) shows the voltage profile of the testing done at $1 \mathrm{~A}\left(44.4 \mathrm{~mA} / \mathrm{cm}^{2}\right)$ and the sample with short circuiting shows an improvement of around $8 \%$ in voltage value compared to the one without short circuit for the old system. There is only one curve for this sample as the short circuiting interval was the same for both the Horizon strategy and the optimised Imperial Arcola strategy. For the new stack, there is an improvement of $10 \%$ (Horizon Strategy) and 
$112 \%$ (Imperial Arcola Strategy) as compared to the testing without any short circuiting. As the

2 short circuiting was removed after 2 hours, the voltage starts to drop gradually which suggests

3 that the surface oxide coverage is beginning to return to its equilibrium value.

Figure 5 (b) shows the voltage profile for the testing done at $2 \mathrm{~A}\left(88.9 \mathrm{~mA} / \mathrm{cm}^{2}\right)$ for both H-100 stacks. The results demonstrate an improvement of $8 \%$ (Horizon Strategy) and $10 \%$

6 (Imperial Arcola Strategy) for both the old and new stack in comparison to no short circuiting.

7 The system follows the same profile as seen in the testing done at $1 \mathrm{~A}\left(44.4 \mathrm{~mA} / \mathrm{cm}^{2}\right)$ when the short circuits is removed after 2 hours. Similar improvements in the range of $10-12 \%$ are observed for both stacks when tested at $3 \mathrm{~A}\left(133.3 \mathrm{~mA} / \mathrm{cm}^{2}\right)$ with short circuiting in comparison to no short circuiting as shown in figure 5 (c). As the old H-100 stack was not able to reach higher currents, only the new stack was tested at $6 \mathrm{~A}\left(266.7 \mathrm{~mA} / \mathrm{cm}^{2}\right)$ and the voltage profile obtained is shown in figure $5(\mathrm{~d})$ with an inset highlighting the profile for $100 \mathrm{~s}$. Similar improvement of 10-12\% are observed by the use of short circuiting as compared to no short circuiting. The testing was not done at even higher current densities due to the limitation of the stack as it is rated for $100 \mathrm{~W}$ and while doing short circuiting at $6 \mathrm{~A}\left(266.7 \mathrm{~mA} / \mathrm{cm}^{2}\right)$, power was around $92 \mathrm{~W}$. Another point to be noted here is that we are able to exceed the performance improvement using our Imperial Arcola strategy compared to the standard Horizon strategy at all the current values. The improvement obtained by the Imperial Arcola strategy is almost $2 \%$ higher in all the cases which suggests that the short circuiting interval is an important factor and it should vary with the operating condition of the stack like current density, temperature. The other advantage using Imperial Arcola strategy is the validation and variation of the short circuiting interval on the condition of stack i.e. new and old in the current study.

The relationship between short circuiting time and the electrochemical double layer capacitance is also important. In order to investigate this, the double layer capacitance was determined by electrochemical impedance spectroscopy. Electrochemical impedance 
1 spectroscopy was done at the same current values which are used above for short circuiting in

2 the frequency range of $10 \mathrm{kHz}$ and $0.1 \mathrm{~Hz}$ with an amplitude of $5 \%$ of the DC current. Figure

36 (a) shows the impedance spectra obtained at different current values. All the spectra are fitted

4 using Z-View using an equivalent circuit consisting of $R_{m}\left(C P E_{1} R_{p}\right)$ where $R_{m}$ is the ohmic

5 resistance, $\mathrm{CPE}_{1}$ is the constant phase element and $\mathrm{R}_{\mathrm{p}}$ is the polarisation resistance. There is a

6 slight decrease in the ohmic resistance with the increase in the current which can be due to the

7 better humidification of the membrane as the current increases. Also the charge transfer

8 resistance decreases with the increase in the current as the driving force for oxygen reduction

9 reaction increases as can be seen at the low frequency values of impedance, as expected by the

10 Butler-Volmer equation. As the electrochemical double layer is modelled as a capacitor, the

$11 \mathrm{RC}$ constant was calculated from the parameter obtained by circuit fitting and the result is

12 shown in Table 1. The RC constant for a capacitor is termed as the time required to charge or

13 discharge $63 \%$ of the capacitor and our theory is that the minimum short circuiting time should

14 be higher than the time needed to discharge the electrical double layer appreciably. It can be

15 seen that the RC constant decreases with the increase in current which is due to the improved

16 oxygen reduction reaction kinetics at the higher current and thus lower resistance. Figure 6 (b)

17 shows the voltage profile obtained at $3 \mathrm{~A}\left(133 \mathrm{~mA} / \mathrm{cm}^{2}\right)$ by varying the short circuiting time

18 from $10 \mathrm{~ms}$ to $500 \mathrm{~ms}$ using a single short circuit. It can be seen that there is only a slight

19 improvement using the short circuiting time of $10 \mathrm{~ms}$ as the double layer is not completely

20 discharged and the effect of the short circuit is not prominent. As soon as the short circuiting

21 time is increased to $50 \mathrm{~ms}$ or above, the improvement is high as the double layer is discharged

22 to a significant amount during this time and the short circuit can induce other effects other than

23 just discharging the double layer. 

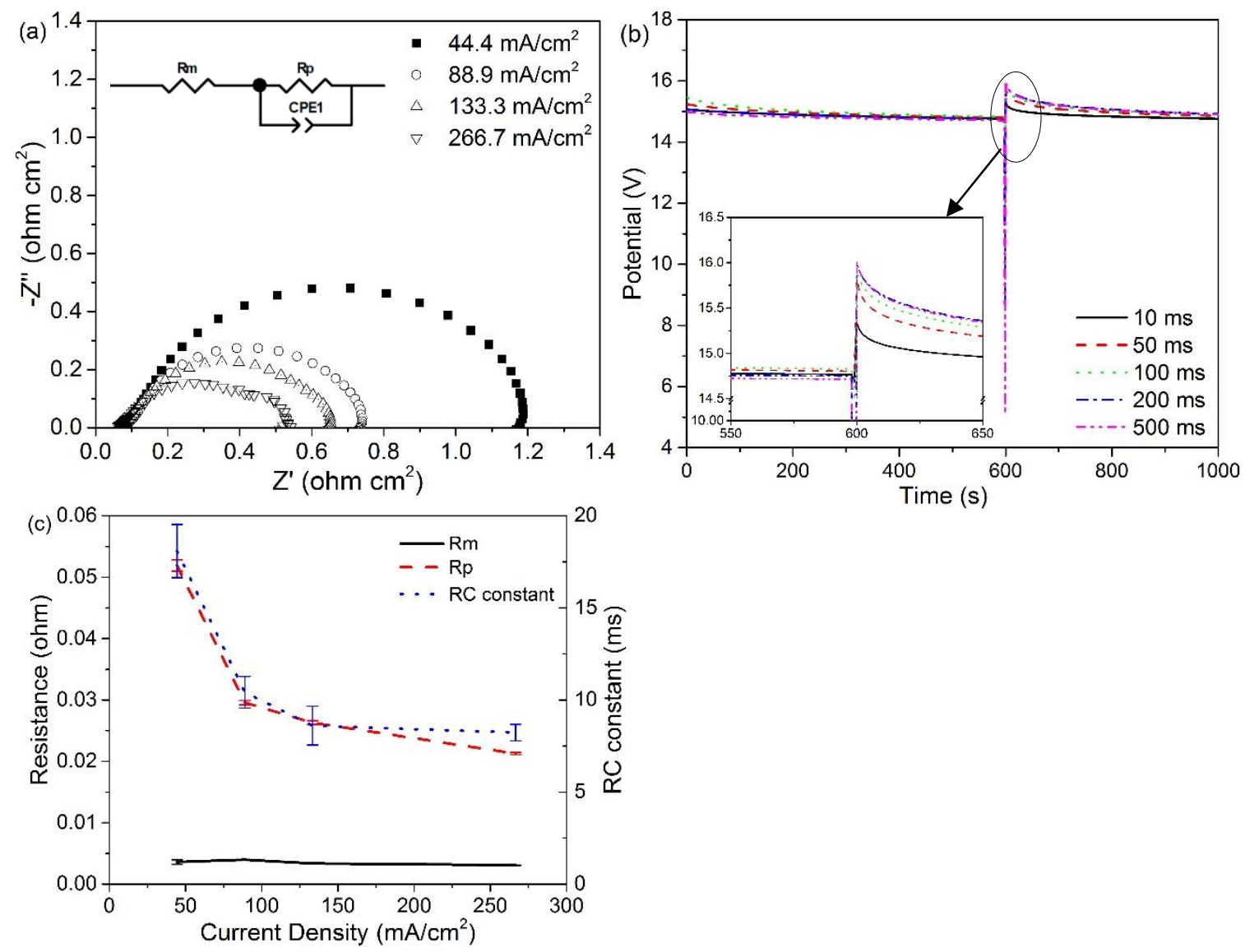

Figure 6: (a) Electrochemical Impedance spectra obtained at different current values for H3100 stack, (b) short circuiting profile obtained at $3 \mathrm{~A}$ for different short circuiting time and 4 (c) variation of resistance and RC constant with current density as calculated by circuit fitting of impedance spectra shown in (a).

\section{Conclusions}

A simple procedure to determine the optimum short circuiting strategy (the Imperial

9 Arcola strategy) has been developed using a single short circuit at different current values. This strategy is based on maximising the cumulative average power density gain and minimising

11 the time required to recover the energy loss during short circuits. This strategy was validated

12 on a commercial H-100 stack using a degraded and new stack and the Imperial Arcola strategy

13 showed an extra improvement of $2 \%$ compared to the standard Horizon strategy recommended

14 for use with H-100 systems. The optimum short circuiting duration and interval was shown to be dependent on the operating conditions of the stack (i.e. current density). An overall 
1 improvement of $10-12 \%$ in voltage for a given current density, and hence power, was

2 demonstrated using short circuiting as compared to no short circuit. capacitance of the fuel cell. If the short circuit duration is too short the charge passed during the short circuit mainly contributes to the discharge of the double layer capacitance rather than stripping of the oxides from the Pt surfaces. We show that by using impedance spectroscopy measurements, the double layer capacitance can be determined and used to ascertain the minimum short circuit time.

[1] Wang Y, Chen KS, Mishler J, Cho SC, Adroher XC. A review of polymer electrolyte membrane fuel cells: Technology, applications, and needs on fundamental research. Applied Energy. 2011;88:981-1007.

[2] Zhang S, Yuan X-Z, Hin JNC, Wang H, Friedrich KA, Schulze M. A review of platinumbased catalyst layer degradation in proton exchange membrane fuel cells. Journal of Power Sources. 2009;194:588-600.

19 Applications. Springer; 2008.

20 [4] Bing Y, Liu H, Zhang L, Ghosh D, Zhang J. Nanostructured Pt-alloy electrocatalysts for 21 PEM fuel cell oxygen reduction reaction. Chem Soc Rev. 2010;39:2184-202. [5] Yu W, Porosoff MD, Chen JG. Review of Pt-based bimetallic catalysis: from model surfaces to supported catalysts. Chemical reviews. 2012;112:5780-817. electrocatalysts for PEM fuel cells. Energy \& Environmental Science. 2011;4:3167. [7] Godínez-Salomón F, Hallen-López M, Solorza-Feria O. Enhanced electroactivity for the oxygen reduction on $\mathrm{Ni} @ \mathrm{Pt}$ core-shell nanocatalysts. International Journal of Hydrogen Energy. 2012;37:14902-10.

[8] Othman R, Dicks AL, Zhu Z. Non precious metal catalysts for the PEM fuel cell cathode. International Journal of Hydrogen Energy. 2012;37:357-72. 
1 [9] Lee W-D, Lim D-H, Chun H-J, Lee H-I. Preparation of Pt nanoparticles on carbon support 2 using modified polyol reduction for low-temperature fuel cells. International Journal of 3 Hydrogen Energy. 2012;37:12629-38.

4 [10] Stamenkovic VR, Mun BS, Arenz M, Mayrhofer KJ, Lucas CA, Wang G, et al. Trends in 5 electrocatalysis on extended and nanoscale Pt-bimetallic alloy surfaces. Nature materials. $6 \quad 2007 ; 6: 241-7$.

7 [11] Antolini E, Salgado J, Gonzalez E. The stability of Pt-M (M=first row transition metal) 8 alloy catalysts and its effect on the activity in low temperature fuel cells. A literature review 9 and tests on a Pt-Co catalyst. Journal of Power Sources. 2006;160:957-68.

10 [12] Gupta G, Sharma S, Mendes PM. Nafion-stabilised bimetallic Pt-Cr nanoparticles as 11 electrocatalysts for proton exchange membrane fuel cells (PEMFCs). RSC Adv. 2016;6:826351243.

13 [13] Markovic NM, Schmidt TJ, Stamenkovic V, Ross PN. Oxygen Reduction Reaction on Pt 14 and Pt Bimetallic Surfaces: A Selective Review. Fuel Cells. 2001;1:105-16.

15 [14] de Bruijn FA, Dam VAT, Janssen GJM. Review: Durability and Degradation Issues of PEM Fuel Cell Components. Fuel Cells. 2008;8:3-22.

17 [15] Steininger H, Lehwald S, Ibach H. Adsorption of oxygen on Pt(111). Surface Science. 1982;123:1-17.

19 [16] Wintterlin J, Zambelli T, Barth JV, Ertl G. Complex pathways in dissociative adsorption 20 of oxygen on platinum. Nature. 1997;390:495-7.

21 [17] Prabhakaran V, Arges CG, Ramani V. Investigation of polymer electrolyte membrane 22 chemical degradation and degradation mitigation using in situ fluorescence spectroscopy. Proceedings of the National Academy of Sciences of the United States of America. 2012;109:1029-34.

[18] Cheng X, Shi Z, Glass N, Zhang L, Zhang J, Song D, et al. A review of PEM hydrogen fuel cell contamination: Impacts, mechanisms, and mitigation. Journal of Power Sources. 2007; 165:739-56.

28 [19] Ishimoto T, Koyama M. A review of molecular-level mechanism of membrane degradation in the polymer electrolyte fuel cell. Membranes. 2012;2:395-414.

30 [20] Gubler L, Dockheer SM, Koppenol WH. Radical (HO , HO and HOO ) Formation 31 and Ionomer Degradation in Polymer Electrolyte Fuel Cells. Journal of The Electrochemical 32 Society. 2011;158:B755. 
1 [21] Nosaka Y, Ohtaka K, Ohguri N, Nosaka AY. Detection of OH Radicals Generated in 2 Polymer Electrolyte Membranes of Fuel Cells. Journal of The Electrochemical Society. 3 2011;158:B430.

4 [22] Ohguri N, Nosaka AY, Nosaka Y. Detection of OH radicals as the effect of Pt particles in 5 the membrane of polymer electrolyte fuel cells. Journal of Power Sources. 2010;195:4647-52. 6 [23] Fuglevand WA, DeVries PD, Lloyd GA, Lott DR, Scartozzi JP. Fuel cell and method for 7 controlling same. Google Patents; 2000.

8 [24] Koschany A, Lucas C, Schwesinger T. Gas diffusion electrode with reduced diffusing 9 capacity for water and polymer electrolyte membrane fuel cells. Google Patents; 2002.

10 [25] Pearson M. Method and apparatus for improving the performance of a fuel cell electric 11 power system. Google Patents; 2004.

12 [26] Pearson MT. Apparatus for improving the performance of a fuel cell electric power system. 13 Google Patents; 2009.

14 [27] Kim J, Kim D-M, Kim S-Y, Nam SW, Kim T. Humidification of polymer electrolyte 15 membrane fuel cell using short circuit control for unmanned aerial vehicle applications. International Journal of Hydrogen Energy. 2014;39:7925-30. [28] Zhan Y, Guo Y, Zhu J, Li L. Current short circuit implementation for performance improvement and lifetime extension of proton exchange membrane fuel cell. Journal of Power Sources. 2014;270:183-92.

20 [29] Newton I. Philosophiæ naturalis principia mathematica. Londini: Jussu Societatis Regiæ 21 ac Typis Joseph Streater; 1686.

22 [30] Motte A. The Mathematical Principles of Natural Philosphy. London1729.

23 [31] Rinaldo SG, Lee W, Stumper J, Eikerling M. Mechanistic Principles of Platinum Oxide 24 Formation and Reduction. Electrocatalysis. 2014;5:262-72.

\section{Acknowledgements}

27 The authors would like to thank Innovate UK for the funding support (MESE_P52011). We would like to thank Arcola Energy and especially Jermu Pulli for their valuable contribution in handling of the project and providing assistance at all time. We would also like to thank Dr Richard Silversides, Mr Vimmendra Patel and Mr Asanka Munasinghe for the useful discussion about the power electronics aspect of short circuiting control. 